\title{
A DANÇA DO REI: O BALÉ DE CORTE E O PODER DE SOBERANIA EM FOUCAULT
}

\author{
W. S. FANTINI \\ Departamento de Filosofia-Universidade Federal da Paraíba (UFPB) \\ wilnesfantini@yahoo.com.br
}

Artigo submetido em novembro/2014 e aceito em fevereiro/2015

DOI: $10.15628 /$ holos.2015.2553

\section{RESUMO}

No presente artigo tecemos algumas análises acerca do funcionamento do poder de soberania em Foucault e as relações desse poder com o corpo do indivíduo e com o surgimento, no domínio da dança, do balé de corte. 0 poder de soberania é um poder de obediência por vincular soberano e súdito. Segundo Foucault, esse poder funciona através de rituais e cerimônias (gestos, hábitos, sinais de respeito, brasões etc.) que se inserem no nível mais elementar do corpo social, pois ele se refere a uma série de poderes microscópicos que penetram nos comportamentos cotidianos e nos corpos dos indivíduos. A efetivação do poder de soberania na área da dança aparece no balé de corte que nasceu na França do século XVI. Esse balé era amiúde uma combinação de arte, de política e de entretenimento.
Além do papel de passatempo para o monarca e sua comitiva, o balé de corte também tinha a função de ratificar o poder soberano. Ao dançar nos balés, o rei fazia lembrar seu poder de controle da cena social, econômica e política. Consequentemente, havia um domínio do monarca sobre os corpos dos indivíduos de tal modo que quando um indivíduo transgredia uma lei, ele atingia o próprio soberano porque a lei era expressão de sua vontade. Até o século XVIII os corpos dos indivíduos eram a única riqueza acessível que legitimava o poder absoluto do soberano e, portanto, há uma relação do poder de soberania e do suplício como punição. As cerimônias dos suplícios eram um ritual cuja função jurídico-política era de reconstituir a soberania lesada por um instante.

PALAVRAS-CHAVE: Michel Foucault, Balé de corte, Poder de soberania, Corpo, Suplício.

\section{KING'S DANCE: COURT BALLET AND POWER OF SOVEREIGNTY IN FOUCAULT}

\begin{abstract}
This article comments some analyses on the working of sovereign power in Foucault and the relations of this power with the body and the appearing, in the field of dance, of court ballet. The power of sovereignty is a power of obedience which binds sovereign and subject. According to Foucault, this power works through rituals and ceremonies (gesture, signs of respect, blazonry) that are introduced in the most elementary level of the social body whereas it is a number of microscopical powers that traverse daily behaviors and our bodies. Power of sovereignty in dance domain appears in court ballet which emerged in France in the sixteenth century. This kind of ballet was a combination of arts, politics and entertainment. Apart from the role of pastime to the
\end{abstract}

monarch and his subjects, court ballet had also the function of sovereign power confirmation. The king reminded his social, economic and politics power control when he danced on the ballets. Consequently, there was a monarch's domain on the bodies in such way that when someone broke a law, he affected the monarch himself because the law was the expression of his desire. Until the eighteenth century the bodies were the only accessible richness that legitimized the sovereign absolutism and, therefore, there is a relation between sovereign power and the torture as a punishment. The ceremonies of tortures were a ritual which juridical political purpose was to reestablish the sovereignty damaged at that instant.

KEYWORDS: Michel Foucault, Court ballet, Power of sovereignty, Body, Torture. 


\section{INTRODUÇÃO}

Ainda que Foucault não tenha escrito sobre a dança ao menos ele fabricou e ofereceu os instrumentos, os utensílios, as armas, os tool-box para que aqueles que lessem os seus livros pudessem encontrar uma ferramenta com a qual se pudesse fazer bom uso dentro do seu domínio. Essas ferramentas só surgem, segundo Foucault, devido à possibilidade que o filósofo tem de falar "[...] de alguma coisa de muito particular, quer dizer, da experiência historicamente definida que é a sua, mas que ele transforma e que a faz valer como uma experiência geral." (FOUCAULT, 2001a, p. 1390). Tendo então essa flexibilidade filosófica de trabalhar sobre todo e qualquer assunto e tendo também as ferramentas necessárias podemos, assim, resgatar o domínio da dança que, de fato, foi esquecido e negligenciado no campo filosófico, uma vez que foram poucos os filósofos que se dedicaram a explorar tal assunto.

No presente artigo, não abordamos o tema da dança como um todo, mas fizemos um recorte bem singular que consistiu em descrever e analisar o período histórico concernente ao Absolutismo Monárquico. Nesse contexto histórico, ponderamos e tecemos considerações sobre o poder de soberania estudado pelo filósofo francês Michel Foucault (1922-1984). Tomando como base o poder de soberania, vimos que, nessa época houve o surgimento e o desenvolvimento - no domínio da dança -, do balé que, inicialmente, foi chamado de balé de corte.

O objetivo da nossa pesquisa foi resgatar a área da dança para as reflexões filosóficas e procurar entender dentro de um período histórico determinado - o Absolutismo Monárquico como se deu a relação do poder de soberania com o surgimento e o desenvolvimento do balé de corte.

\section{A DANÇA DO REI: O BALÉ DE CORTE}

Se fizermos um sobrevoo de um modo geral pelos períodos da História da dança, desde a Antiguidade até o momento presente, podemos afirmar que decorreu o seguinte trajeto: foi-se dos templos, passando pelas praças das aldeias, depois pelos salões até chegar aos palcos.

As danças, na Antiguidade, na maioria das vezes, eram executadas dentro dos templos apenas por sacerdotes e iniciados e pouco a pouco foram sendo extensas à população que passou a participar dos cultos. As danças de domínio religioso, por terem agora a participação popular, foram também usadas em outros tipos de celebração como em casamentos e na louvação pela boa colheita. Com o tempo, as danças foram também sendo executadas fora do âmbito dos templos e passaram a ocupar as praças das aldeias. Essa transferência do domínio estrito dos sacerdotes para o campo do povo causou o aparecimento da dança como manifestação popular. Um dos motivos dessa transição se deveu ao fato de que algumas danças populares eram usadas para expressar a insatisfação do povo contra as proibições da Igreja durante as festas e celebrações pagãs (CARLÉS, 2012; FARO, 1998). Isso não significa dizer que as danças populares tenham perdido completamente o cunho religioso. É sabido que muitas manifestações populares guardam uma forte ligação com a religiosidade, mas houve uma expansão da dança para um número maior de participantes, a saber, a população de um modo 
geral, quanto a modificação e a inserção de gestos que antes não existiam no campo da dança religiosa propriamente dita.

Outra mudança no campo da dança se deu com o surgimento do feudalismo na Europa e todas as alterações políticas e sociais que se seguiram às invasões bárbaras. Nessa época, a dança se manteve afastada do desenvolvimento artístico do seu tempo tendo como uma das razões primordiais a mentalidade cristã que exaltava muito mais o lado contemplativo e espiritual e condenava qualquer manifestação relacionada ao corpo que era considerado impuro e pecaminoso. "O que é inegável é que esta separação ocasionada por motivos históricos e sociais, prolongada durante séculos, fez com que a dança se mantivesse um tanto deslocada em sua própria natureza e tardou tanto tempo em voltar a emergir como atividade artística." (CARLÉS, 2012, p. 23).

Esses acontecimentos históricos tiveram grande importância na transferência das danças das praças das aldeias para os salões da nobreza. Consequentemente, podemos aludir que as danças de salão, que floresceram na realeza europeia, descenderam diretamente das danças populares. Essas danças foram transferidas do chão de terra das aldeias para o chão de pedra dos castelos medievais, e, por conseguinte, sofreram algumas modificações, por exemplo, o abandono do que se considerava nelas de menos nobre (FARO, 1998).

A transição das danças populares das aldeias para o âmbito da nobreza fez surgir, na França ${ }^{1}$, os balés de corte. Esse tipo de balé aparece no século XVI vinculado ao Renascimento ${ }^{2}$ italiano especialmente do período denominado de Quattrocento ${ }^{3}$ e sua evolução deu-se ao longo do século XVII, em que o Barroco ${ }^{4}$ já se fazia presente na cultura europeia (CHRISTOUT, 1975; MONTEIRO, 2006).

A forma específica do balé de corte consistia no desenvolvimento de um tema (que poderia ser mitológico, romanesco ${ }^{5}$, burlesco ${ }^{6}$ ou político) que era exposto a partir de danças que compõem diversas entrées ${ }^{7}$, entremeadas por recitativos e cantos (MONTEIRO, 2006). Em suma,

\footnotetext{
${ }^{1}$ Tanto a França quanto a Itália contribuíram para o desenvolvimento do balé de corte, pois as cortes de ambos os países desenvolveram espetáculos grandiosos apresentados entre o curso de um banquete, em atos de uma peça, em entradas reais numa cidade ou em eventos especiais, a exemplo dos casamentos aristocráticos (AU, 1988).

${ }^{2}$ O Renascimento foi um movimento cultural, em geral, considerado entre os séculos XIV a meados do século XVI que surgiu na região de Toscana na Itália, tendo como características principais o Humanismo e o Antropocentrismo. O nome "Renascimento" é oriundo da redescoberta e do resgate das referências culturais da Antiguidade Clássica greco-romana.

${ }^{3}$ O Quattrocento foi a fase áurea do Renascimento que compreendeu o movimento cultural italiano presente na região de Florença do século XV (BOURCIER, 2001).

4 O Barroco floresceu entre o final do século XVI e meados do século XVII, inicialmente na Itália tendo posteriormente se difundido por outros países da Europa e da América. De certo modo, o Barroco, pelo menos inicialmente, compartilha o mesmo interesse pela Antiguidade Clássica que o Renascimento, embora as abordagens artísticas das obras barrocas tenham ganhado outro olhar ao interpretar o mundo, o homem e a religiosidade. É importante observar que o barroco, na França, se manifesta na moda e na dança, diferentemente do barroco na Itália e na Espanha, mais presente na pintura, na escultura e na poesia (MONTEIRO, 2006).

${ }^{5} \mathrm{O}$ Romanesco é o que tem caráter romântico e de romance.

${ }^{6}$ O Burlesco é uma categoria estética próxima da sátira e da paródia e que por isso, usa recursos satíricos, tais como termos cômicos, arcaicos e vulgares para caricaturar.

${ }^{7}$ Entrées era o nome que se dava a um trecho dançado por um ou mais bailarinos. Define a unidade coreográfica; equivaleria, no teatro, à cena. Nos balés de corte “[d]eterminadas entrées podem ser reaproveitadas de um balé para o outro, mas o sentido delas no desenvolvimento de um determinado tema deve ser desconhecido e original.
} 
o balé de corte organizava-se a partir de três importantes elementos: (1) a ação dramática (que envolvia o desenvolvimento do tema utilizando poesias e cantos), (2) a dança geométrica em que os dançarinos faziam evoluções geométricas tais como círculos, losangos, retângulos em uma determinada parte da sala. Essas formas geométricas eram concebidas para serem vistas do alto uma vez que os espectadores eram dispostos em bancadas e (3) as entrées ou árias "[...] reservadas a temas específicos ou tradicionais: [como as] entrées de fúrias, de demônios, de combatentes, cuja dança era livre, ou improvisada e que recorriam muitas vezes à mímica e à acrobacia." (BOURCIER, 2001, p. 74).

O primeiro balé de corte surgiu em 1564 com seus elementos constituintes de dança, de música, de poesia, de cenários com máquinas ligados a uma ação dramática. Nesse primeiro balé, o rei é representado por Júpiter que coordenava o mundo, garantindo-lhe harmonia e paz. 0 segundo balé de corte, que possuía um estilo diferente do do primeiro, teve como finalidade a apresentação do reino da França aos senhores espanhóis pela rainha Catarina de Médicis ${ }^{8}$ (15191589). O referido balé foi dançado por grupos de moças que representavam as dezesseis províncias daquele reino (BOURCIER, 2001).

Vários outros balés surgiram ao longo dos anos, todavia aquele que estabeleceu e fixou por algum tempo esse gênero de dança como "balé de corte" foi o Ballet comique de la reine no ano de 1581. O aludido balé foi executado durante o reinado de Catarina de Médicis, em comemoração ao casamento do duque de Joyeuse e de Marguerite de Lorraine-Vaudémont. A rainha quis celebrar a festa com um balé que, por sua vez, não ficou pronto a tempo para a celebração de casamento que ocorreu entre os dias 18 a 24 de agosto de 1581 e só pôde ser apresentado no dia 15 de outubro do mesmo ano na sala Bourbon do Louvre (BOURCIER, 2001).

O que fez com que o Ballet comique de la reine se tornasse o marco do balé de corte? Podemos alegar que foi a maneira como ele foi estruturado: seguindo a fórmula dos costumes da época para um balé que deveria ter a ação falada, a cantada e a dançada, Balthasar de Beaujoyeux ${ }^{10}$ - seu idealizador - fixou uma forma que foi seguida e aperfeiçoada através dos anos: um "[...] prólogo em homenagem ao rei, [as] entrées em diversos tons, que se inscrevem numa ação coordenada [...], [o] uso do canto e da dança misturados; a poesia declamada [...]." (BOURCIER, 2001, p. 88-89). Além disso, o posicionamento do rei e da rainha que ficavam sob o dossel no fundo da sala e a localização do público, ao redor, nas bancadas.

Ademais, pela primeira vez, é dançado um final que se tornará tradicional no balé de corte: o grande balé do qual participam todos os nobres em trajes que também se tornarão tradicionais (penacho na cabeça, máscaras em geral dourada, túnica curta que deixava as pernas

\footnotetext{
As entrées nunca vistas, assim como os figurinos originais, atestam maior capacidade de invenção. A invenção aparece ou pela novidade do material ou pela novidade da combinação." (MONTEIRO, 2006, p. 37-38).

${ }^{8}$ Com o objetivo social e político de manter a corte distraída durante boa parte do tempo, a rainha Catarina de Médicis importou da Itália artistas e cortesãos especializados na preparação de luxuosos espetáculos. Esses espetáculos, que não passavam de um elegante passatempo para o monarca e sua corte, eram uma combinação de dança, canto e texto falados. Vale salientar que os custos com os cenários e as roupas luxuosas dos espetáculos eram provenientes do dinheiro recolhidos dos impostos que o povo pagava (FARO, 1998).

${ }^{9}$ Esse balé (que teve a duração de aproximadamente cinco horas e meia!) contou a história de Circe em cenas que apresentavam alegorias morais, históricas e cortesãs (CARLÉS, 2012).

${ }^{10}$ O Ballet comique de la reine foi criado pelo italiano Balthasar de Beaujoyeux, cujo verdadeiro nome era Baldassarino de Belgioso.
} 
nuas). Logo após o grande balé, havia um baile do qual toda a corte participava (tantos os nobres performers quanto os espectadores) (AU, 1988; BOURCIER, 2001).

Após termos conhecimento de que a partir do Ballet comique de la reine se fixou o gênero do balé de corte tantos outros balés apareceram ${ }^{11}$ em sequência seguindo a mesma fórmula estética.

Já vimos como eram organizados os balés de corte, porém, será que eles possuíam alguma função?

De fato, os balés de corte possuíam algumas funções: (1) uma delas era sócio-política de passatempo para o monarca e sua comitiva, justamente por combinarem os temas políticos com o desejo de prazer e de diversão; (2) outra função era a de etiqueta, que atingiu seu apogeu no reinado de Luís XIV e cujas danças mostravam a hierarquia social e os comportamentos, já que as danças de corte, em geral, eram consideradas um meio de socialização do indivíduo fazendo parte da educação do cavalheiro; e (3) a de ratificar o poder soberano. Essa função de confirmação do poder real estava estritamente vinculada aos motivos políticos desenvolvidos e dançados nos balés de corte.

Das três funções recentemente apresentadas, iremos salientar a última (confirmação do poder real) porque ela é a expressão do poder soberano. E para que entendamos essa lógica da ratificação do poder soberano nos balés de corte iremos descrever o que seria o poder de soberania segundo o filósofo francês Michel Foucault.

\section{PODER DE SOBERANIA}

Um dos tipos de poder que Foucault distingue nas suas análises é o poder de soberania. Esse poder possui algumas características, dentre elas, vincular soberano e súdito. Isso indica que se trata de um poder de obediência. Foucault esclareceu que para que houvesse relação de soberania era preciso que existisse um direito divino, uma conquista, uma vitória, um ato de submissão, um juramento de fidelidade e um ato firmado entre o soberano que concedia privilégios, ajuda e proteção, e alguém que, em compensação, retribuísse esses favores com empenho e trabalho. Outra característica desse tipo de poder é que a relação de soberania é frágil e tende à ruptura. Consequentemente, uma maneira de manter a relação funcionando é a existência do que Foucault denominou de "reatualização", que seriam rituais e cerimônias, tais como gestos, hábitos, obrigações de comprimento, sinais de respeito, brasões etc. De acordo com isso, o filósofo francês aludiu que

a corte tem essencialmente como função constituir, organizar um lugar de manifestação cotidiana e permanente do poder monárquico em seu esplendor. No fundo, a corte é essa espécie de operação ritual permanente, recomeçada dia após dia, que requalifica um indivíduo, um homem particular, como sendo o rei, como sendo o monarca, como sendo o soberano. A corte, em seu ritual monótono, é a operação incessantemente renovada pela qual um homem que se levanta, que passeia, que come, que tem seus amores e suas paixões, é ao mesmo tempo, através disso, a partir disso e sem que nada disso seja de algum modo eliminado, um soberano. Tornar seu amor soberano, tornar sua

\footnotetext{
${ }^{11}$ Na França, do ano 1589 ao ano 1610, enumeram-se mais de oitocentos balés! (CHRISTOUT, 1975).
} 
alimentação soberana, tornar soberanos seu despertar e seu deitar: é nisso que consiste a operação específica do ritual e do cerimonial da corte. (FOUCAULT, 1997, p. 209-210).

Poderíamos destacar como mais uma característica do poder de soberania, o fato de ele não ser uma relação isotópica, ou seja, ele não constitui um quadro hierárquico unitário. $\mathrm{Na}$ realidade, o poder de soberania possui relações heterogêneas umas em relação às outras, como a relação do senhor e do escravo que difere da do senhor feudal com o suserano que já difere da do padre com relação ao leigo e que difere ainda das relações familiares. À vista disso, todas essas relações não podem ser integradas no interior de um sistema verdadeiramente único (FOUCAULT, 2006).

Foucault assegurou que é bastante frequente a questão do poder, de um modo abrangente, ser tomada de acordo com o modelo prescrito pelos pensamentos jurídico-filosófico do século XVI e do século XVII que, reduziam o problema do poder ao problema da soberania ao se perguntar: "[...] o que é o soberano? Como o soberano pode se constituir? O que liga os indivíduos ao soberano?" (FOUCAULT, 2001b, p. 231). No entanto, o filósofo francês quis mostrar outra direção em referência a esse poder soberano: que a soberania política insere-se no nível mais elementar do corpo social, indo "[...] de súdito a súdito [...], entre os membros de uma mesma família, nas relações de vizinhança, de interesses, de profissão, de rivalidade, de ódio e de amor [...]" (FOUCAULT, 2003, p. 215). Ou seja,

entre cada ponto de um corpo social, [...] passam as relações de poder que não são a projeção pura e simples do grande poder soberano sobre os indivíduos; elas são muito mais o solo móvel e concreto sobre o qual ele vem se ancorar, as condições de possibilidade para que ele pudesse funcionar. (FOUCAULT, 2001b, p. 232).

O poder de soberania trata-se de um poder político sem limites na relação cotidiana e, por isso mesmo, é bastante temível, pois cada um pode tornar-se para o outro um monarca terrível e cruel.

Após essa breve exposição e descrição do que seria o poder de soberania segundo a concepção de Foucault, apresentaremos, a seguir, a efetivação desse tipo de poder nos balés de corte.

O poder de soberania aparece nos balés de corte em algumas ocasiões: (1) no momento da escolha dos temas, que independente se eram motivos mitológicos, políticos, romanescos ou burlescos sempre procuravam destacar a pessoa do rei. Por exemplo, quando a temática referiase ao Cosmo percebia-se que havia uma posição hierárquica bem definida dos corpos celestes como a Terra, o Sol e a Lua. A disposição desses corpos celestes exprimiam as relações de poder dentro da corte.

Se o mote era político, a exemplo do que se verificou no reinado da rainha Catarina de Médicis $^{12}$ (1519-1589), que teve como finalidade apresentar aos senhores espanhóis o reino da

\footnotetext{
${ }^{12}$ Com o objetivo social e político de manter a corte distraída durante boa parte do tempo, a rainha Catarina de Médicis importou da Itália artistas e cortesãos especializados na preparação de luxuosos espetáculos. Esses espetáculos, que não passavam de um elegante passatempo para o monarca e sua corte, eram uma combinação de
} 
França que foi representado por grupos de moças cuja dança descrevia as dezesseis províncias daquele referido reino (BOURCIER, 2001).

Outro balé com a mesma temática, La défense du paradis (A defesa do paraíso), que foi dançado no dia 20 de agosto de 1572 fez referência ao casamento de Henrique de Navarra e Margarida de Valois na sala Bourbon do Louvre, que, por sua vez, se tornou, por muito tempo, o local de representação dos grandes balés. Esse balé fez "[...] alusão ao casamento que deveria trazer a paz entre católicos e protestantes [...]" (BOURCIER, 2001, p. 83). Tratou-se "[...] claramente de um balé de propaganda, que expõe alegoricamente o estado da França: os protestantes vencidos serão liberados pela clemência do rei, e a paz será garantida. Propaganda ilusória: três dias depois, seria noite de São Bartolomeu ${ }^{13}$." (BOURCIER, 2001, p. 84).

(2) Os cenários também mostram seu vínculo com o poder de soberania. $O$ balé já citado, La défense du paradis, que fez menção ao casamento de Henrique de Navarra e Margarida de Valois trouxe, por exemplo, o rei Carlos IX num carro alegórico em forma de cavalo marinho dourado em que o rei apareceu "[...] vestido de Netuno, rodeado de príncipes e senhores que dançavam." (BOURCIER, 2001, p. 82). No balé Arième, de 1596, dançado em homenagem ao governador da Bretagne, o duque de Mercoeur,

[o]s cenários foram pintados sobre as superfícies de pentágonos; sua manobra, operada por um maquinista debaixo deles, permitia mudanças visíveis pelos espectadores. [...] Além disso, a maquinaria comportava um globo que descia dos arcos, onde estava Júpiter [cujo papel era provavelmente desempenhado pelo rei], em meio a trovões e raios. (BOURCIER, 2001, p. 93).

O Ballet de Minerve (O balé de Minerva), composto em 1615 pelo poeta de corte Étienne Durand, apresentou um cenário que corroborou com um tema de propaganda do reinado de Maria de Médicis, mãe de Luís XIII. A rainha enfrentava problemas internos que ameaçavam seu reinado e decidiu "[...] fortalecer sua autoridade destruindo as alianças desejadas pelo rei falecido e tentando se aproximar da Espanha." (BOURCIER, 2001, p. 94). Essa aproximação com a Espanha se deu através de um duplo casamento entre sua filha Elizabeth, que se une a Filipe IV da Espanha, e Luís XIII, que fica noivo de Ana d'Áustria. O ballet de Minerve realizou-se antes da partida de Elisabeth e contou com uma entrada da alegoria dos Vapores noturnos. A terra, os rochedos, as ondas, os dançarinos, os pastores e os tritões anunciaram a vinda triunfal de Minerva - que representava a rainha Maria de Médicis - num "[...] carro levado por Amores, seguida de amazonas, coroada pelo Renome e pela Vitória.” (BOURCIER, 2001, p. 95).

(3) Outra aparição do poder soberano nos balés de corte se fez com relação aos personagens. O rei ou a rainha sempre desempenhava um papel de destaque e, dentro da história contada pelo balé de corte, eles sempre eram os vencedores temidos e admirados por todos. No primeiro balé de corte, surgido em 1564, por exemplo, o rei foi representado por

dança, canto e texto falados. Vale salientar que os custos com os cenários e as roupas luxuosas dos espetáculos eram provenientes do dinheiro recolhidos dos impostos que o povo pagava (FARO, 1998).

${ }^{13}$ A guerra entre católicos e protestantes durou muito anos na França. Em 1570 foi selado um acordo de paz, conhecido como Tratado de Paz de Saint-Germain, entre ambas as partes. Contudo em 1572, poucos dias após o casamento entre Henrique de Navarra e Margarida de Valois (princesa da França e filha da rainha Catarina de Médicis) houve o que ficou conhecido na história como o massacre da noite de São Bartolomeu, que se deu na madrugada entre os dias 23 e 24 de agosto daquele ano em que dezenas de milhares de protestantes foram massacrados por católicos, devido a guerras religiosas. 
Júpiter, que coordenava o mundo, garantindo-lhe harmonia e paz. Outro exemplo foi o personagem desempenhado pelo rei Luís XIV, em 1653, na parte derradeira da apresentação do Ballet de la nuit ${ }^{14}$ - sobre o triunfo final - que apareceu pela primeira vez com o papel de Sol do qual foi titular em todos os balés seguintes. Ao representar o Rei Sol, Luís XIV se tornou a personificação do brilho e do esplendor do poder soberano (BOURCIER, 2001).

Assim, ao dançar nos balés e nos bailes, o rei fazia lembrar aos demais, seu poder de dominação e de controle da cena social, econômica e política. De tal forma que "[...] nos balés em que o rei dança, os outros dançarinos se ordenam ao redor dele, significando que ninguém pode dançar, pensar e agir independentemente da autoridade real" (FAURE, 2001, p. 36). Não é à toa que, na composição dos balés de corte, havia uma relação entre os papéis sociais do soberano, dos homens e mulheres da corte e dos súditos, na vida real e na representação cênica. Essa função de propaganda e de ratificação do poder de soberania desempenhada por esses tipos de balés estava muito presente até o reinado de Luís XIII ${ }^{15}$.

Essa associação mútua e intrínseca entre a vida social e política da corte e o balé confirma, ainda mais, que os estudos sobre o poder que Foucault realizou referem-se a toda essa série de poderes cada vez mais tênues, microscópicos, que penetram profundamente os comportamentos cotidianos e os corpos dos indivíduos. Um ponto importante a ser destacado é a conexão entre o poder de soberania e os corpos dos indivíduos.

[...] Foucault nos conta que até o século XVIII o corpo dos indivíduos era essencialmente a superfície da inscrição dos suplícios e das penas, pois o corpo era a "única riqueza acessível" que legitimava o poder absoluto do soberano. Nas monarquias do fim da Idade Média, quando um indivíduo transgredia uma lei, ele atingia e transgredia a própria vontade do soberano: a lei era expressão de sua vontade. As cerimônias dos suplícios eram, [...], um ritual político tão importante quanto o coroamento do rei. [...] [O]s gritos de dor e os pedidos de clemência e perdão do criminoso deviam exprimir o poder do soberano. A cerimônia do suplício tinha o corpo do condenado como suporte. Há, aqui, uma polaridade que nos dá um "corpo duplo": o corpo do rei e o corpo do condenado. Este corpo não deve ser interpretado como metáfora, mas, sim, como uma realidade política; a presença do corpo é fundamental para o funcionamento das monarquias. (CARDIM, 2009, p. 128-30).

Logo, havia uma relação estreita entre o poder de soberania, o corpo e a punição que nessa época era o suplício.

Étienne Durant foi o autor do balé de corte Jerusalém délivrée que foi escolhido por Luís XIII para anunciar sua vontade em intervir e em assumir efetivamente o poder, a que será feito no ano de $1617^{16}$, ou seja, três meses depois do assassinato - tramado pelo próprio Luís XIII - do marechal Concini (BOURCIER, 2001).

\footnotetext{
${ }^{14}$ Michaut (1945) afirmou que o Ballet de la nuit tinha, como tema principal, a adulação do rei.

${ }^{15}$ Luís XIII (1601-1643) apreciava muito os balés, não somente participava deles como ator (ele tinha gosto pelos papéis de personagens grotescos malvestidos e pelos de mulher), mas, também, como autor, uma vez que compôs uma suíte em dezesseis entrées, denominado o Ballet de la Merlaison (BOURCIER, 2001).

${ }^{16}$ Luís XIII permanece afastado dos negócios e passa seu tempo a caçar com um membro da corte muito próximo a ele chamado Luynes. Enquanto isso, o governo de Maria de Médicis está desacreditado e o verdadeiro poder está
} 
O assunto desse balé exaltou, portanto, a libertação de Luís XIII da regência de sua mãe, Maria de Médicis, e marcou a grandeza, a glória e a soberania do rei: o personagem do demônio do fogo, que era o rei Luís XIII, tinha o poder de “"[...] purgar seus súditos de qualquer desobediência'. Na cena final, o rei estabelece pela primeira vez, prefiguração do que será gradualmente elaborado e completado por Luís XIV, uma etiqueta de distanciamento" (BOURCIER, 2001, p. 97).

Porém, um acontecimento que ocorreu "por trás dos bastidores" - se assim podemos dizer - do citado balé, reporta-nos à questão do suplício: Étienne Durant, por ter escrito panfletos contra Luynes - amigo próximo do rei Luís XIII - foi condenado, passou pelo suplício da roda e foi queimado em Grève (BOURCIER, 2001).

Servindo-nos do exemplo acima citado sobre o suplício de Étienne Durant, a seguir serão apresentadas algumas considerações sobre o corpo supliciado segundo as reflexões de Foucault.

\section{O ESPETÁCULO DO CORPO SUPLICIADO}

De início poderíamos pensar que o suplício era a exasperação da crueldade e da selvageria do poder do monarca, personificado na pessoa do carrasco. Todavia, Foucault fez uma interessante interpretação desse acontecimento do suplício que, embora nos possa parecer estranho, é uma técnica. Se se trata de uma técnica não pode corresponder a uma punição corporal qualquer, nem a extremos de uma raiva sem lei, nem a caprichos do rei, nem ao exagero "[...] de uma justiça que, esquecendo seus princípios, perdesse todo o controle." (FOUCAULT, 2008, p. 32). O suplício é "[...] um ritual organizado para a marcação das vítimas e a manifestação do poder que pune [...]" (FOUCAULT, 2008, p. 32). Até o século XVIII ele desempenhava muito mais o papel de uma cerimônia política do que o de uma reparação moral. Por essa razão, o filósofo francês observou:

Uma pena para ser um suplício [...] deve [...] produzir uma certa quantidade de sofrimento que se possa, se não medir exatamente, ao menos apreciar, comparar e hierarquizar[...]. O suplício repousa na arte quantitativa do sofrimento. Mas não é só: esta produção é regulada. O suplício faz correlacionar o tipo de ferimento físico, a qualidade, a intensidade, o tempo dos sofrimentos com a gravidade do crime, a pessoa do criminoso, o nível social de suas vítimas. Há um código jurídico da dor; a pena, quando é supliciante, não se abate sobre o corpo ao acaso ou em bloco; ela é calculada de acordo com regras detalhadas: número de golpes de açoite, localização do ferrete em brasa, tempo de agonia na fogueira ou na roda (o tribunal decide se é o caso de estrangular o paciente imediatamente, em vez de deixá-lo morrer, e ao fim de quanto tempo esse gesto de piedade deve intervir), tipo de mutilação a impor (mão decepada, lábios ou línguas furados) [...]. Em relação à vítima, [...] o suplício [...] traça em torno, ou melhor, sobre o próprio corpo do condenado sinais que não devem se apagar; a memória dos homens, em todo caso, guardará a lembrança da exposição, da roda, da tortura ou do sofrimento devidamente constatados [...]. Nos "excessos" dos suplícios, se investe toda a economia do poder. (FOUCAULT, 2008, p. 31-32).

sob a regência do marechal d'Ancre Concini que é assassinado três meses antes de Luís XIII assumir definitivamente o poder (BOURCIER, 2001). 
O objetivo principal do suplício, portanto, não consistia na morte ${ }^{17}$, propriamente dita, mas numa morte-suplício que seria a arte de reter a vida no sofrimento, de retardar a morte ao máximo numa requintada agonia ${ }^{18}$.

Já ressaltamos que, na visão de Foucault, o suplício é uma técnica. Mas qual seria, de fato, sua função? Nessa época o delito "[...] era considerado como um desafio à soberania do monarca [pois] ele perturbava a ordem de seu poder sobre os indivíduos e sobre as coisas." (FOUCAULT, 2001a, p. 1594). Por conseguinte, a função do suplício é jurídico-política cuja finalidade é reconstituir a soberania lesada por um instante, ou seja, é:

[...] fazer funcionar, até um extremo, a dissimetria entre o súdito que ousou violar a lei e o soberano todo-poderoso que faz valer sua força [...]. E esta superioridade não é simplesmente a do direito, mas a da força física do soberano que se abate sobre o corpo de seu adversário e o domina: atacando a lei, o infrator lesa o corpo de seu adversário e o domina: atacando a lei, o infrator lesa a própria pessoa do príncipe: ela - ou pelo menos aqueles a quem ele delegou sua força - se apodera do corpo do condenado para mostrá-lo marcado, vencido, quebrado [...]. O suplício não restabelecia a justiça; reativava o poder (FOUCAULT, 2008, p. 42-43).

O caráter espetacular do suplício era um ato público e, assim, fazia com que o povo participasse desse reconhecimento do poder excessivo do monarca.

\section{CONCLUSÃO}

A partir do que foi exposto, podemos entender, então, que, o período do Absolutismo Monárquico possuiu relações de poder, uma noção de corpo e discursos próprios. Isso significa dizer que em cada época existem nuanças, variações, detalhes que aparecem quando se pensa, se problematiza ou se escreve algo sobre a história da loucura, do sexo, da punição ou da dança.

Foucault considerava os momentos históricos como descontínuos e os fatos concretos como singularidades, em vez de considerar a história como algo universal e global. Logo, fundando-nos nesse modo de pensar do filósofo francês, observamos que assim como a história da psiquiatria não é a história da loucura, como defendeu Foucault em História da loucura na Idade Clássica, a história do balé não pode ser considerada a história da dança como afirmou

\footnotetext{
17 Mesmo que o objetivo primordial do suplício não fosse a morte, Foucault esclarece, nas obras, Em defesa da sociedade e História da sexualidade: a vontade de saber (volume I) que havia, no poder de soberania, o que o filósofo francês chamou de o direito da vida e da morte, ou mais precisamente, o direito de fazer morrer ou de deixar viver. O rei poderia exercer um poder direto ou indireto sobre a vida dos súditos. O poder indireto era exercido quando, por exemplo, o rei se sentia ameaçado por inimigos exteriores que queriam contestar seus direitos reais e, então, ele poderia legitimar uma guerra e ordenar aos sujeitos fazer parte da defesa do Estado. Já o poder direto era exercido quando um súdito ia de encontro ao poder real que, neste caso, significava ir contra o próprio rei. A título de castigo, o rei poderia matá-lo (FOUCAULT, 1976). Em suma, “[...] o súdito não é, de pleno direito, nem vivo nem morto. Ele é, do ponto de vista da vida e da morte, neutro, e é simplesmente por causa do soberano que o súdito tem direito de estar vivo ou tem direito, eventualmente, de estar morto. Em todo caso, a vida e a morte dos súditos só se tornam direitos pelo efeito da vontade soberana." (FOUCAULT, 1997, p. 286).

${ }^{18}$ Foucault (2001a) indica que a invenção da guilhotina foi um momento de mudança qualitativa no castigo, por ser uma máquina que transforma a agonia do sofrimento do suplício em grau praticamente zero de sofrimento, uma vez que não há o retardo da morte, ao contrário, a morte é rápida.
} 
Arnold Haskell ao dizer que: "o balé é uma arte moderna; a dança é pré-histórica. A história do balé é apenas um momento de toda a história da dança." (HASKELL apud FARO, 1998, p. 29).

Assim sendo, poderíamos compreender que não há nem "a loucura" nem "o balé" como uma categoria universal. Ao invés disso, existem "loucuras" ou "balés", justamente por haver nuanças, diferenças ou, nas palavras de Foucault, singularidades.

Vimos que o balé apresentou e representou (e ainda hoje apresenta e representa) os estilos de vida, a etiqueta, os comportamentos, as relações de poder e a concepção de corpo de uma determinada época.

\section{REFERÊNCIAS BIBLIOGRÁFICAS}

1. AU, S. Ballet \& Modern Dance. London: Thames and Hudson Ldt., 1988.

2. BOURCIER, P. História da dança no Ocidente. (APPENZELLER, M. Trad.). 2. ed. São Paulo: Martins Fontes, 2001

3. CARDIM, L. N. Foucault: a história política do corpo - disciplina e regulamentação. In Corpo. (pp. 127-143). Col. Filosofia frente \& verso. São Paulo: Globo, 2009.

4. CARLÉS, A. A. Historia del ballet y la danza moderna. 2. ed. Madrid: Alianza editorial, 2012.

5. CHRISTOUT, M-F. Histoire du ballet. 2. ed. Paris: Presses Universitaires de France, 1975.

6. FARO, A. J. Pequena história da dança. 4. ed. Rio de Janeiro, Jorge Zahar Ed, 1998.

7. FAURE, S. Corps, savoir et pouvoir: sociologie historique du champ choréografique. Presses Universitaires de Lyon, 2001.

8. FOUCAULT, M. A vida dos homens infames (1977). Trad. RIBEIRO, V. L. A. In: Estratégia, poder-saber. Col. Ditos \& Escritos IV. Rio de Janeiro: Forense Universitária, 2003. p. 203-222.

9. FOUCAULT, M. Dits et ecrits I (1954-1975). Paris: Gallimard, 2001a.

10. FOUCAULT, M. Dits et ecrits I/ (1976-1988). Paris: Gallimard, 2001b.

11. FOUCAULT, M. Droit de mort et pouvoir sur la vie. In: Histoire de la sexualité I: la vonlonté de savoir. Paris: Gallimard, 1976. p. 175-211.

12. FOUCAULT, M. Em defesa da sociedade. Curso no Collège de France (1975-1976). Trad. GALVÃO, M. E. São Paulo: Martins Fontes, 1997.

13. FOUCAULT, M. Microfísica do poder. 22. ed. Rio de Janeiro: Graal, 2006.

14. FOUCAULT, M. Vigiar e punir: o nascimento da prisão. Trad. RAMALHETE, R. 35. ed. Petrópolis, RJ: Vozes, 2008.

15. MICHAUT, Pierre. Histoire du ballet. Paris: Presses Universitaires de France, 1945.

16. MONTEIRO, M. Noverre: cartas sobre a dança. 1. ed. 1. reimpr. São Paulo: Editora da Universidade de São Paulo: FAPESP, 2006. 